\title{
ГИБРИДИЗАЦИЯ НАЦИОНАЛЬНЫХ ОБРАЗОВАТЕЛЬНЫХ СИСТЕМ
}

\section{HYBRIDIZATION OF NATIONAL EDUCATIONAL SYSTEMS}

\section{A. Makarova}

Summary: This article analyzes the definition of «hybridization» and determines its relevance, considered as a tool for scientific analysis and modernization of the national educational reality, determines its relevance as a projected perspective system of education of a new level, which is appropriate to use as a rational system of higher quality. The process of becoming a hybridization of national educational systems is a primary factor that will allow integrating the international context of structural transformations of foreign experience into the domestic one and increase the competitiveness of the entire educational model of higher schools in Russia, to reach the first positions in the market of international educational services.

In contrast to the known classic options that, in light of recent trends in the labour market and the global Informatization of society and economic conditions of education, are losing their relevance, the hybrid nature of the modernization of the educational space for national systems at the interface of vocational education, vocational training and higher education, it is important to examine, through the prism of the Bologna system.

The Bologna process allows national educational systems to gradually grow from state to international frameworks, and to form a unified educational and scientific space as the most effective form of implementing the tasks and orders of the modern labor market.

Keywords: modernization of the system of higher education system, hybrid education systems, hybridization of higher education, Bologna process, educational reforms.
Л юбая попытка сравнивать национальные системы высшего образования, которые являются структурообразующим фактором всей профессиональной жизни каждого индивида, наталкивается на различные ограничения, поскольку такие системы встроены в другие социальные подсистемы (например, трудовые отношения, базовое образование, профессиональное образование, характеристики кадрового потенциала и т.д.).

Согласно исследованиям В.С. Сенашенко, А. Макаровой (2018), в настоящий момент в России существует искусственная система образования, которая порождает искаженные образовательные формы, деструктурирующие отечественную систему высшего образования из-за смещения концептов и целей образовательной деятельности и создания инвертированных структур, что

\author{
Макарова Амина Андреевна \\ Ассистент, Российский университет дружбы народов, \\ 2. Москва \\ makarova-aa@rudn.ru
}

Аннотация: В данной статье анализируется дефиниция «гибридизация» и обусловливается ее актуальность, рассматриваемая в роли инструмента научного анализа и модернизации национальной образовательной реальности, определяется ее релевантность как прогнозируемой перспективной системы образования нового уровня, которую целесообразно использовать в качестве рациональной системы более высокого качества. Непосредственно процесс становления гибридизации национальных образовательных систем является первостепенным фактором, который позволит интегрировать международный контекст структурных преобразований зарубежного опыта в отечественный и повысить конкурентоспособность всей образовательной модели высших школ России, выйти на первые позиции рынка международных образовательных услуг.

В отличие от известных классических вариантов, которые, в свете последних тенденций на рынке труда и глобальной информатизации социума, а также экономических условий функционирования образования, теряют свою актуальность, гибридный характер модернизации образовательного пространства для национальных систем на стыке профессионального образования, профессиональной подготовки и высшей школы важно рассматривать сквозь призму болонской системы.

Болонский процесс позволяет постепенно перерастать национальным образовательным системам из государственных рамок в международные, сформировать единое образовательное и научное пространство как наиболее эффективную форму реализации задач и заказов современного рынка труда.

Ключевые слова: модернизация системы высшего образования, гибридные образовательные системы, гибридизация высшего образования, болонский процесс, образовательные реформы.

искривляет представление о сущности трансформации образовательной реальности [14, с. 24].

Современное педагогическое пространство Болонского процесса, для которого характерно, в первую очередь, углубление межгосударственного сотрудничества в сфере образования [1, с. 14], активно внедряемое как на международном уровне, так и в отечественном пространстве, характеризуется межэтнической и межконфессиональной толерантностью и поликультурной средой обучения.

Учет тенденций Болонского процесса и его интеграция в программу высших российских школ в роли основного компонента гибридизации национальных образовательных систем, интерпретируется современными международными организациями, как одно из основных 
условий роста привлекательности и конкурентоспособности вузов [11, с. 46].

Согласно опыту мировой образовательной среды, гибридизация предполагает интеграцию не только различных национальных систем, но и потенциальное сотрудничество с зарубежными партнерами, иностранными фирмами и регулярную миграцию граждан из России и эмиграцию из страны в различные государства, актуализируемые профессиональным контекстом сотрудничества, так как «одной из приоритетных задач современного российского обучения в высшей школе, согласно Национальной доктрине образования, является интеграция России в мировое образовательное пространство, взаимопроникновение и взаимовлияние культур» [8], а также интернационализация высших учебных заведений, как основного механизма Болонского процесса, стремительно набирающего обороты в Европе и России [5, с. 23] и в других развитых странах.

В том числе, исходя из результатов конференции европейских министров, посвященной «Болонскому процессу 2020», подчеркивается, что программы высшего образования должны включать, в качестве обязательного компонента, междисциплинарный подход в обучении $[5$, с. $12 ; 10$, с. 114$]$.

В исследованиях А.С. Кац (2018) подчеркивается сущность содержания интеграции системы отечественных высших школ, базирующаяся на принципе комплиментарности, социально значимой и единой по своей структуре и содержанию. При этом первостепенное условие международной образовательной интеграции в отечественное пространство - это реализация принципов российского высшего образования в условиях массового объединения и сохранения духовного наследия, развитие творческого и научного потенциалов, сохранение таких лучших педагогических традиций, как фундаментальность отечественного высшего образования [4, с. 37].

Гибридизация высших школ «становится одной из ключевых тенденций углубления международных образовательных контактов» и становится «следствием процессов глобализации» $[1 ; 6 ; 9]$, при этом подразумевает не только конгломерацию существующих форм, но и создание новых [9; с. 14, с. 25], т.е. «процесс, ориентированный на формирование нового образа высшей школы» [2, с. 121], «интеграцию национальных систем образования для создания единого образовательного пространства» [7, с. 20], а также диверсификацию форматов получения образования и создание единого социокультурного пространства [3, с. 3]. Таким образом, гибридизация образования, которая в международном контексте является следствием глобализационных процессов, представляет собой взаимное проникновение образовательных идей, концепций, теорий и представлений различных стран в системы традиционного национального образования [15, с. 884].

По мнению В.С. Сенашенко, А. Макаровой (2018), формирование национальных образовательных систем сквозь призму гибридизации связано с модернизацией системы высшего профессионального образования, представляемой тремя векторами: 1) структурный, коррелирующий с обновлением структуры образовательных учреждений для рационализации их функционирования; 2) технологический, подразумевающий совершенствование технологического оснащения учебного процесса; 3) информационный, определяемый содержанием образовательных программ [15, с. 888]. Полагаем, что здесь целесообразно дифференцировать еще такой социально обусловленный вектор модернизации, как ментальность - импонирование общественностью педагогически ценным компонентам и специфике международно-ориентированного обучения, начиная от принятия важности зарубежного опыта и инновационных процессов, оканчивая реорганизацией подходов к кадровому потенциалу.

Нами схематизирован алгоритм гибридизации национальных образовательных систем в контексте российского высшего образования (см. рис. 1).

Согласно алгоритму, представленному на рисунке 1, национальное образовательное пространство включает в себя как педагогическую инноватизацию образовательного процесса, предполагающую антропологический фактор и компьютеризацию образовательного внутривузовского пространства, так и творческий потенциал, который в настоящее время на международном рынке труда требует от специалиста не только профессиональной компетенции и научных знаний, но и креативность мышления, нестандартные вариативные подходы к решению поставленных задач, самостоятельность и ответственность за их выполнение, а также навыки работать в коллективе, который характерен своей динамикой в культурном, конфессиональном, национальном аспектах.

\section{BывOА}

Гибридизация современного образования высших школ, ориентированных на обучение специалистов с учетом социального заказа, релевантности кадрового потенциала и международных тенденций в рамках инновационных специальностей и подходов к выполнению различного рода труда, от интеллектуального до физического, подразумевает принятие международного опыта с учетом лучших отечественных педагогических традиций. Ориентированность на зарубежные новации подразумевает под собой непрерывность образо- 


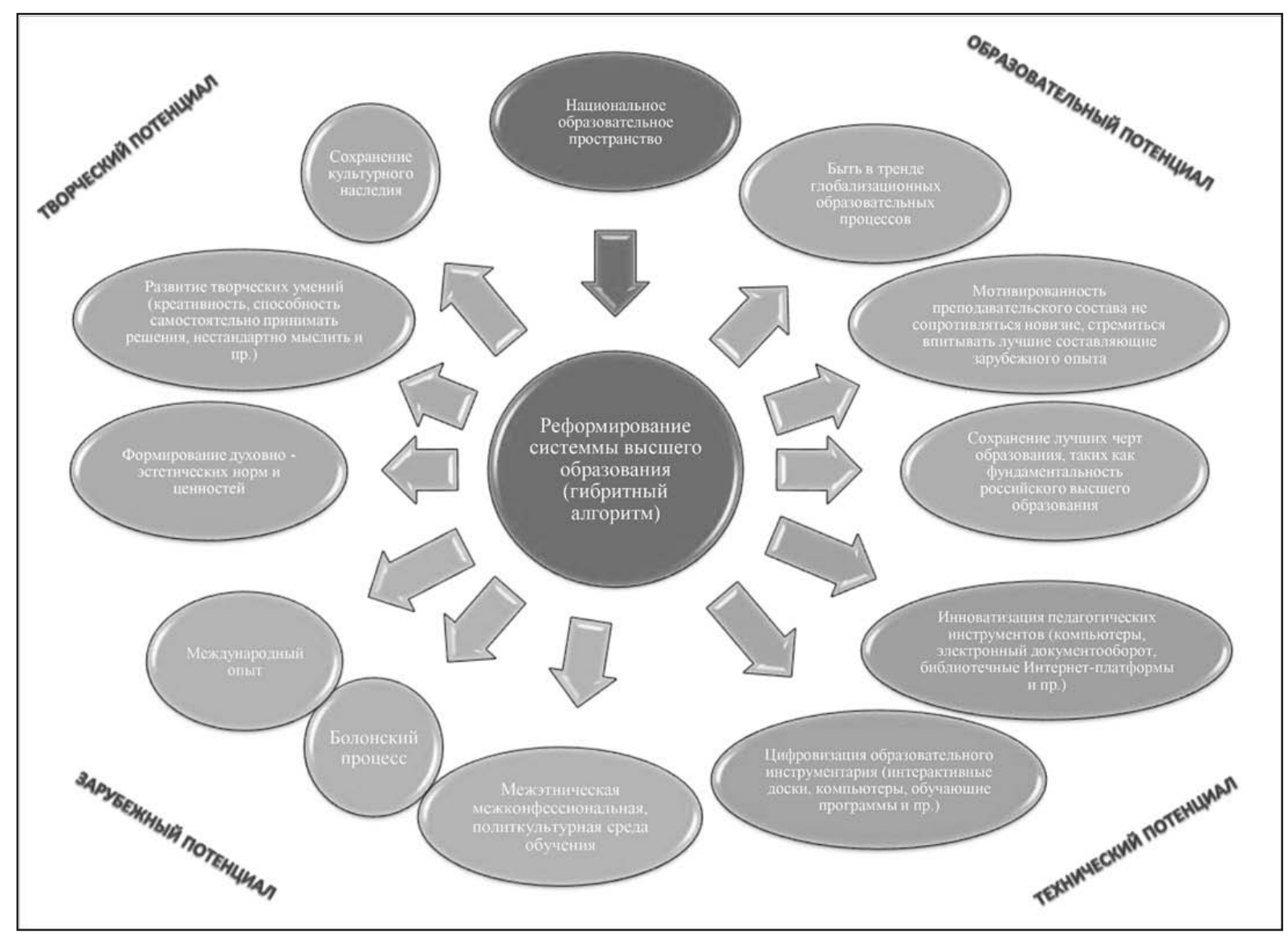

Рис. 1. Алгоритм гибридизации национальных образовательных систем

вательного процесса без отрыва от практического использования знаний по изучаемой специальности. При этом педагогические процессы высших школ должны консолидироваться с экономическими, политическими и социальными преобразованиями на отечественном и зарубежном рынках труда.

Гибридизация национальных образовательных систем не предполагает копирования международных концепций, а подразумевает конгломерацию существующих российских и иностранных форм в сочетании с созданием новых. При этом гибридизация включает в себя как научно-теоретическое обоснование, как одно из наиболее сложных социальных явлений, так и учет образовательного и творческого потенциалов в контексте российской ментальности, с сохранением культурных и духовно-этических ценностей.

\section{ЛИТЕРАТУРА}

1. Ананин, Д.П. Социально-педагогические условия профессиональной подготовки учителей в рамках Болонского процесса: на примере Федеративной Республики Германия: автореферат дисс. ... кандидата педагогических наук: 13.00.08 / Ананин Денис Павлович; [Место защиты: Алт. гос. пед. акад.]. Барнаул, 2015. -24 c.

2. Байденко, В.И. Многоплановый и системный характер Болонского процесса (статья вторая) / В.И. Байденко // Высшее образование в России. - 2009. №9. - С. $120-132$.

3. Жаркова, А.А. Социально-культурное развитие студенческой молодежи в условиях глобализации культурно-образовательного пространства: автореферат дисс. ... кандидата педагогических наук: 13.00.05 / Жаркова Анна Александровна; [Место защиты: Казан. гос. ун-т культуры и искусств]. - Казань, 2015. $-24 \mathrm{c}$.

4. Кац, А.С. Формирование межэтнической толерантности студентов в поликультурной среде вуза: дисс. ... кандидата педагогических наук: 13.00 .01 / Кац Александра Семеновна; [Место защиты: Ин-т педагогики, психологии и соц. проблем]. - Казань, 2018. - 255 с.

5. К Красильникова, Н.В. Интернационализация образовательного процесса в вузах Европейского союза: на примере университетов Италии: дисс. ... кандидата педагогических наук: 13.00.01 / Красильникова Надежда Валентиновна; [Место защиты: Сарат. нац. исслед. гос. ун-т им. Н.Г. Чернышевского]. 
- Йошкар-0ла, 2017. - 214 с.

6. Маклюэн, М. Понимание Медиа: внешние расширения человека / Маршалл Маклюэн; пер. с англ. В.Г. Николаева. - 2-е изд. - Москва: Гиперборея: Кучково поле, 2007. -462 с.

7. Оразалина, 3.3. Формирование технологической готовности преподавателя вуза к использованию виртуальной образовательной среды при кредитной технологии обучения: на примере Республики Казахстан: дисс. ... кандидата педагогических наук: 13.00.08 / Оразалина Зауре Замангазьевна; [Место защиты: Алт. гос. пед. акад.]. - Барнаул, 2015. - 244 с.

8. Постановление Правительства РФ от 04.10.2000 № 751 «0 национальной доктрине образования в Российской Федерации».

9. Сенашенко, В.С. Образовательная гибридизация как результат глобализации сферы образования / В.С. Сенашенко, А.А. Макарова // Конгресс «Глобалистика-2017». Секция «Глобализация и образование» - 2017. - С. 1 - 3.

10. Сулейманова, А.Р. Проектирование образовательных маршрутов аспирантов на основе анализа подготовки научно-педагогических кадров в России и за рубежом: дисс. ... кандидата педагогических наук: 13.00.08 / Сулейманова Алсу Расиховна; [Место защиты: Ин-т педагогики и психологии профессионального образования РА0]. - Казань, 2015. - 263 с.

11. Теребина, П.В. Педагогические условия реализации международной академической мобильности студентов: дисс. ... кандидата педагогических наук: 13.00.08 / Теребина Полина Владимировна; [Место защиты: Чечен. гос. ун-т]. - Пятигорск, 2018. - 253 с.

12. Шакирова, А.А. Развитие академической мобильности студентов в России и Германии: дисс. ... кандидата педагогических наук: 13.00 .01 / Шакирова Алина Альбертовна; [Место защиты: Казан. (Приволж.) федер. ун-т]. - Казань, 2018. - 250 c.

13. Rowe, W. (1991) Memory and modernity. Popular culture in Latin America / W. Rowe6 V. Schelling // Verso, London. - 243 pp.

14. Senashenko, V.S. (2018) Educational Hybrids in Russian Higher Education / V.S. Senashenko, A. Makarova // Высшее образование в России. - №7. - C. 24 - 42.

15. Senashenko, V.S. (2019) Formation of Hybrid Educational Structures in Russian Engineering Education / V.S. Senashenko, A. Makarova // In book: Linear and Nonlinear Programming. M.E. Auer, T. Tsiatsos (Eds.). - Pp.884-894.

(c) Макарова Амина Андреевна (makarova-aа@rudn.ru).

Журнал «Современная наука: актуальные проблемы теории и практики»

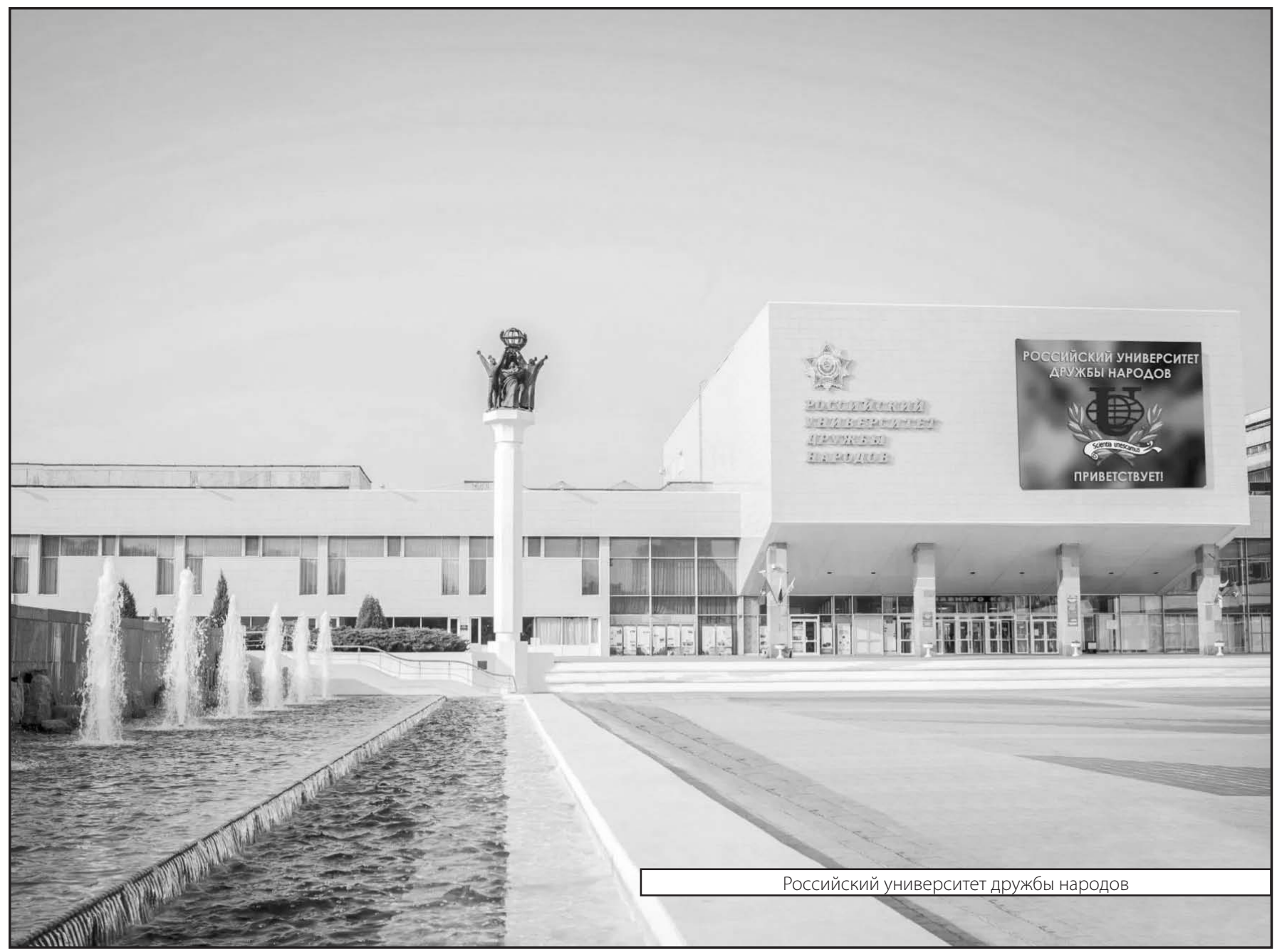

